\title{
A Highly Effective Copper Nanoparticle Coupled with RGO for Electrochemical Detection of Heavy Metal Ions
}

\author{
Dan $\mathrm{Li}^{l}$, Chongxu Wang ${ }^{2}$, Hui Zhang ${ }^{2}$, Youyi Sun ${ }^{2, *}$, Qianqian Duan ${ }^{l}$, Jianlong Ji ${ }^{l}$, Wendong Zhang ${ }^{l}$, \\ Shengbo Sang, \\ ${ }^{1}$ Intelligent Control System of the Ministry of Education and Key Lab of Advanced Transducers \& \\ College of Information Engineering, Taiyuan University of Technology, Taiyuan 030024, China. \\ ${ }^{2}$ Shanxi Province Key Laboratory of Functional Nanocomposites, North University of China, Taiyuan \\ 030051, P.R.China. \\ *E-mail: sangshengbo@tyut.edu.cn
}

doi: $10.20964 / 2017.11 .19$

Received: 28 June 2017 / Accepted: 26 August 2017 / Published: 12 October 2017

\begin{abstract}
A highly effective copper nanoparticle (CuNP) coupled with reduced graphene oxide was successfully prepared by liquid phase reduction. The as-prepared products were tested with X-ray diffraction, fieldemission transmission electron microscopy, and scanning electron microscopy. CuNPs were distributed averagely on the surface of reduced graphene oxide. CuNP/RGO nanocomposites modified bare glassy carbon electrode was measured by electrochemical impedance spectroscopy and cyclic voltammetry. The availability of CuNP/RGO nanocomposites was analyzed by square wave anodic stripping voltammetry (SWASV). The nanocomposites showed a high electroanalytical activity and eximious sensitivity to $\mathrm{Hg}(\mathrm{II}), \mathrm{Cu}(\mathrm{II}), \mathrm{Cd}(\mathrm{II})$ and $\mathrm{Pb}(\mathrm{II})$, these ions exhibited sensitivities of 27.76, $25.86,66.30$ and $50.17 \mu \mathrm{A} / \mu \mathrm{M}$, respectively, and the limits of detection were $0.051,0.111,0.203$ and $0.186 \mu \mathrm{M}$, respectively. The CuNP/RGO nanocomposite was used firstly to detect individually and simultaneously various heavy metal ions. Furthermore, CuNP/RGO/GCE has good anti-interference properties and stability. In this study, CuNP/RGO nanocomposites are presented as a potential material to detect individually and simultaneously heavy metal ions.
\end{abstract}

Keywords: CuNP/RGO, SWASV, electrochemical measurement, heavy metals.

\section{$\underline{\text { FULL TEXT }}$}

(C) 2017 The Authors. Published by ESG (www.electrochemsci.org). This article is an open access article distributed under the terms and conditions of the Creative Commons Attribution license (http://creativecommons.org/licenses/by/4.0/). 